\title{
An Integration of SAR Time Series, Optical Data and Archival Documentation for the Identification of Hypogea as a Possible Factor of Vulnerability in Rome
}

\author{
A. Celauro*a, J.A. Palenzuela Baena ${ }^{a}$, I. Moriero $^{a}$, M.A. Marsella ${ }^{a, b}$ \\ ${ }^{a}$ Department of Civil and Environmental Engineering - Sapienza Università di Roma, Via

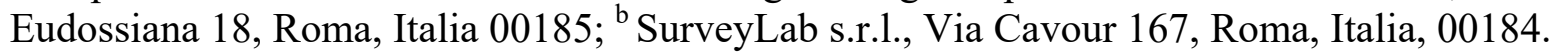

\begin{abstract}
In Rome, the expansion of urbanization, the increase of population density, and the subsequent escalation of traffic are common factors in road infrastructure vulnerability, especially when these aspects coexist with the presence of ancient subterranean environments, such as ancient tuff quarries. These wide networks of subterranean structures are often in endangered preservation conditions, also because their position and extension are only partially known. Furthermore, the aerial bombing attacks that the city of Rome experienced during the II World War are considered here as another critical factor favouring ground instability processes.

In the present research, the joint exploitation of SAR dataset, "historical photograms", and vectorization of historical records have been applied on circumstanced test areas to estimate the quarries' dimension and typology and to evaluate their conservation state related to these anthropogenic aspects.

The aims were addressed mainly with the twofold use of the SAR Cosmo-SkyMed dataset, from the processing of both intensity and phase information contents. The intensity has been used to distinguish low and high backscattering anomalies attributed to the presence of open cast and subterranean structures. The phase information was processed from SAR long time-series, through the PSInSAR method, to test its performance in monitoring cavity stability state. The extraction of Permanent Scatterers was carried out to evaluate its suitability to detect entities of displacement through a wide time span, especially using interpolation maps, to identifying patterns related to ancient hypogea.

This stratification of information has been analyzed around endangered areas. Using this method to analyze the features mentioned, a relationship between these anthropic factors and sinkholes was revealed.
\end{abstract}

Keywords: Rome, roads, instability, underground cavities, ancient quarries, SAR dataset, PSInSAR, SAR Intensity Time Series, photogrammetry.

\section{INTRODUCTION}

In the city of Rome, traffic network infrastructure instabilities, such as sinkholes or chasms, are often related to the presence of extensive systems of underground environments, very often related to ancient activities of rock extraction. This phenomenon is recognized but not wholly quantifiable, given the vast extension of the network of quarries, their only partial mapping and their endangered state of conservation, especially in certain districts of Rome. These are the areas of Rome where the local tuff, coming from the geological districts of the Colli Albani Volcano, was easily extractable as a building material of good quality, exploited from the Roman period up to contemporary times. At the time of the exploitation of this lithic material, these city areas were mainly rural, while now, after the urbanization boom of the ' $80 \mathrm{~s}$, these quarters are highly populated. The increase of inhabitant density and the induced heavy traffic over these ancient hypogeal environments can lead to further structural vulnerability of road surface, that ravels heavily, and of other superficial urban infrastructures, causing an increase of sinkholes. In this article, the contribution of an additional anthropogenic factor is evaluated: that of the iterated bombing attacks during the II World War that can have further diminished the competence of the vaults and pillars of the quarries, developing through time in structural damages that propagates to the surface. The proposed mixed methodology, composed of the joint use of optical photogrammetry, SAR time series data and historical documentation, also allows the assessment of the structural susceptibility in relation to the type of underground quarries and their state of conservation.

\subsection{State of the Art}

The anthropogenic cavities in an urban environment have always been the subject of speleological, archaeological, geological, geotechnical and civil engineering studies. The instability phenomena attributable to them [1][2] in the territory of Rome have been investigated in the fields of civil engineering and risk management by several authors 
[3][4][5]. From these points of view, in the last years, new insights have been achieved. A considerable number of cavities have been mapped and characterized [4][6] and their state of conservation has been evaluated. Moreover, the cause-effect relationship has been addressed by analyzing potential environmental impact of advanced degeneration conditions in the underground and the development of road raveling and sinkholes [7][5]. Additionally, their associated susceptibility assessment [8][2] has been evaluated, and geomatic monitoring has been applied to their stability state and the intervention methods for their stabilization has been developed[3]. A further aim of current research is to identify precursor signals that can allow safety actions instead of emergency interventions [9][10]. As far as monitoring methods are concerned, space-borne, UAV-borne and GB-InSAR satellite interferometry RADAR techniques are widely used. In addition, techniques such as GPS RTK or microgravimetry, drone photogrammetry are also widely applied [11][12][13]. It is worth noting the effectiveness of the PSInSAR technique, which has been widely used in monitoring infrastructure displacement in urban and remote areas $[14][15][16][17]$. The objective of this article mainly addresses the connectivity between the urban instability with ancient anthropic factors. The used methodology builds on a previous long-lasting research activity [18], focused on the identification of features belonging to ancient mining and habitative archaeological landscape through geomantic procedures, developed for the area of Centocelle in Rome (Archaeological Park and surrounding areas).

\subsection{The selection of two cases of study}

In this study, there are three susceptibility factors under consideration: the presence of ancient underground cavities of the quarry/mine-type, the type of these cavities and their state of conservation, the incidence of repeated bombardments in the previous century, which could influence incidence of instability phenomena in recent times. The knowledge of the aforementioned factors has allowed the selection of two study areas, which present a coexistence of these factors, as it will be explained in detail in the following paragraphs. The first area of interest (AOI) is a wide zone in the east of the city, straddling the urban municipi V-VII (named AOI 1, fig.1 in blue), where a vast network of tuff galleries and chambers is present, dug in a broad period since the Roman time till the contemporary period, in the "lionato" and "Villa Senni" local lithotypes. Moreover, this area had a strategic role in the period of the II World War, being here a military airport, military barracks, railway stations and junctions, and important communication routes. For this reason, it has been subject to repeated attacks by the allied air force. Furthermore, as emerges from recent research [5] and from the local news, this zone has had a high incidence of sinkholes events in recent times. Likewise, in a second area in the south-west of Rome, straddling municipi IX and XI (AOI 2, fig.1 in red, sub-area A: Fosso della Magliana/ Fosso della Torretta, sub-area 2: Decima), numerous ancient gravel quarries open up on the right and left banks of the Tiber. Furthermore, this peripheral area of Rome had often been the subject of air attacks due to the presence of bridges, railway stations and military targets. In addition, the area has also been in the local news for problems of road raveling. Therefore, the two areas have elements in common but a substantial diversity of urban texture: the first is intensely urbanized despite having large urban parks, while the second is less inhabited and has large wild green areas. Such concomitances of factors but also dissimilarities allow the setting of a multipurpose methodology for its proper consideration under different conditions.

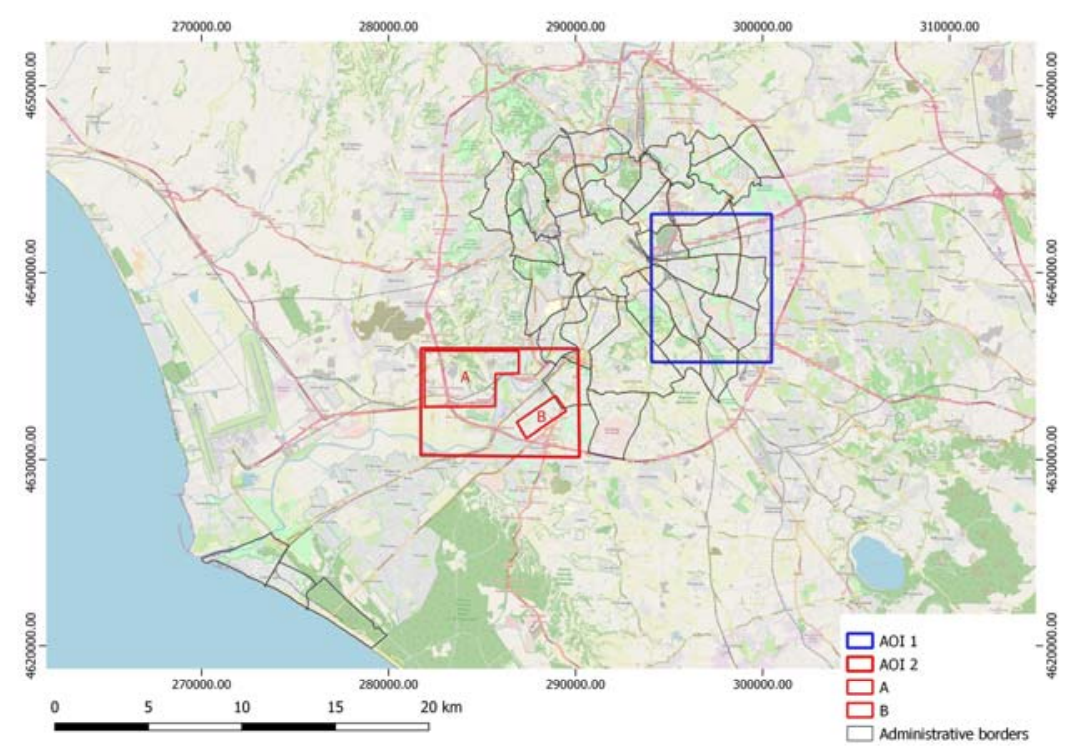

Fig.1: the localization of the two case studies: AOI 1, in blue and AOI 2 in red (A: Fosso della Magliana, B:Decima) 


\section{MATERIALS AND METHODS}

The applied methodology combines historical and archival research with remote sensing monitoring methods. The preliminary phase consisted of the collection of historical archive data related to the three factors herein considered: the ancient quarries, their typology and bombing events. A final cataloguing of relevant information has been performed in vector format, exploitable as georeferenced data. This step of work allowed selecting the two zones under study as reported in the previous paragraph. The here so-called "historical photograms" are photograms acquired during aerial photogrammetric flights in a period between 1920-1970, which allow the study of the topography in periods prior to the current one. Orthorectification, mosaicing and DEM extraction were performed on photograms acquired by the Italian and English airforces (RAF 1944, AM 1953) or photogrammetric institutions (SARA 1928). With the historical DEMs (from SARA 1927, RAF 1944 and AM1953), some of the structures relating to the underground quarry areas and the visible collapsed areas were identified and vectorized in polygon vector layers. By the study of the 3D models via the use of photogrammetric programs such as PCI Geomatica and $3 \mathrm{D}$ point cloud processing software such as Cloud Compare and GigaMesh, the dimensions in the 3D space (perimeters, depth, profiles) have been evaluated, allowing to define the type of quarry structures (chambers and pillars) and the relative age of sinkholes. Instead, a detailed work was dedicated to the localization and vectorization of the bombing events that occurred in 1943-1944 from historical sources, and the accurate vectorization of impact craters visible in RAF 1944 photograms was done in point vector layers (following orthorectification).

Regarding the interferometric data analysis and traditional monitoring, the first operation performed was processing the CSK Ascending and descending dataset in the timespan 2016-2021. Both geometries of acquisition have been considered for PS extraction, intending to compare the distribution of the velocity values, to exclude any artefacts due to the acquisition geometry or to the residual topographic ramps effect and to minimize the effect of radar shadow. For this purpose, the ENVI software - SARSCAPE module and the operational workflow Interferometric Stacking - Persistent Scatterers was used. The PS datasets were then interpolated on the cumulative speed values in mm_yr. This interpolation was performed using a tool developed by Dr. Jose Palenzuela for the European project MUSA (Monitoring Bilt-Up Area from Satellite) and specifically dedicated to the treatment of PS in urban areas. The tool allows the automatic execution of an IDW and 3 types of ordinary kriging (with different variograms and specified for different parameters, such as anisotropy ratio, anisotropy angle, nugget micro variance, slope for linear variogram, power for power variogram). A first exploratory analysis of the spatial data was performed first of all to understand the density of the points, to assist the interpolation of the subsequent datasets for the choice of the more suitable search radius and cell size of the output rasters. A search radius of $50 \mathrm{~m}$ proved to be the best to have a high probability of considering at least five neighboring points in the statistics. Tests were also carried out with higher and lower radii $(20,80,100)$ to check the balance between over and underfitting. Subsequently, a study of the Clusters and Outliers was conducted in ArcGIS (Spatial Statistic Toolbox, which uses the Anselin Local Moran's I) to verify that the subsequent interpolations are not causing a loss of information from the PS values and that the rasters of output are capable of identifying the significative clusters extracted by the tool. Following this preparatory phase, the automated interpolation phase was performed, launched in batch. In addition, the work continued with an analysis addressed to the areas with more negative values of vel. $\mathrm{mm}$ yr values in the interpolated maps to see any correspondence with recent sinkholes events, but also with the other shapefiles created and described previously. The interpolated maps were interrogated with a pool of recent sinkholes events to see any concomitances with the clusters studied. The sinkholes events taken into consideration were extracted from the news of Rome that can be found online for the period between 2018-2021. Each data entry was recorded in the form of a shapefile reporting a general address, position, and the news's date. In the area of Centocelle, once all the outputs have been produced, visual cross-matching evaluations were carried out between the possible factors considered, which, in combination with environmental factors, may have favored sinkholes events in subsequent periods. In the area of Magliana, specifically nearby Via Fosso della Magliana, Via Fosso della Torretta and Monte delle Piche, a SAR Intensity Time Series workflow was performed to recognize structures related to quarry activities and for a characterization of their relative age.

\section{RESULTS}

\subsection{Collection of historical information and their recording in vector format}

An extensive cataloguing activity of historical information relating to the bombing events in Rome [19][20] during the II World War, conducted throughout the whole urban area and registered in a polygon vector layer, has allowed the identification of the most affected areas (fig.2). The most frequent targets were military areas, strategic logistic connection points and areas for maintaining roads or transport vehicles. It is here hypothesized that the impact of the bombs (generally 500 pounds - about $250 \mathrm{~kg}$ ), whose destructive effect was amplified by the explosion, did not generally cause the immediate collapse of the underground cavities but could have had a structural shock effect on 
the static of vaults and pillars of the underlying underground (compressive stress of the pillar and vault, fractures, warping). In fact, considering that the distance between the vaults of the underground environments and the walking level above them was often higher than 5-10 m, the impact rarely caused an immediate collapse of the underground environment. This is also confirmed by historical photograms such as SARA 1944, which will be discussed in the next paragraph, in which it is visible that the impact cause only a not very deep crater of about 10 meters in diameter. On the other side, these structural shocks can affect underground structures, making them more susceptible to subsequent collapse, which can therefore occur decades later, under the increased compressive stress due to the intense urbanization that took place after the 70 s and the relative intensification of the traffic. In this operational phase, it was highlighted that the districts with the highest frequency of bombing events are Tuscolano and Prenestino-Centocelle, which have a frequency of 6 bombing events in a year (1943-1944), especially in strategic areas such as some connection roads such as the Via del Mandrione and Via Casilina (as it will be shown in fig. 9, vectorialized in green), railway stations and junctions, airports. In the area south of Rome, the district most affected at the end of the armed conflict is instead that of Magliana-Quadraro, where the areas near the Magliana Bridge are hit to destruction.
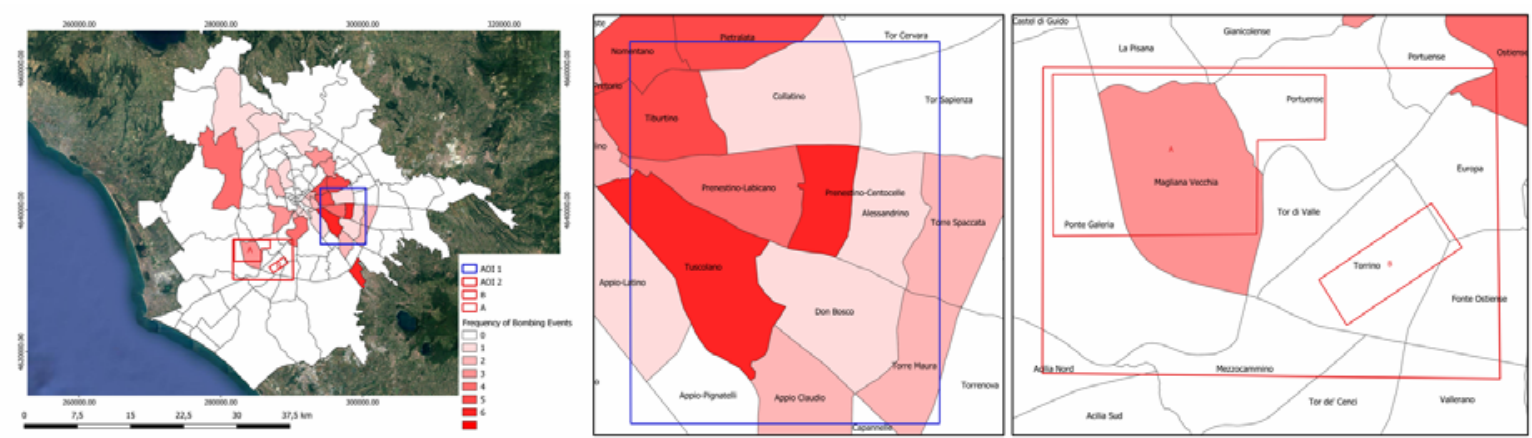

Fig. 2: Image on the left shows a) general map showing the vector file of the bombing events with its symbology set on the frequency (AOI 1 in blue and AOI 2 in red). In the second and third images, a detail of the two AOIs is shown, with the name of the neighbourhoods.

As already mentioned, this operation of cataloguing historical information in vector format, carried out throughout the city's territory, has allowed the identification of the two eligible areas of AOI1 and AOI2, as in the paragraph dedicated to the case studies.

\subsection{Processing of "historical photograms" for the vectorization of 2D and 3D features}

The "historical photograms" showing quarry structures and relative sinkholes (SARA 1927, AM 1953) or impact craters (RAF 1944) were chosen for photogrammetric processing, aimed primarily at orthorectification and the extraction of "historical" DEMs. For what concerns the bombing events, these frames, once orthorectified, allowed the location of the areas hit by bombing in the Centocelle / Osteria del Curato district (fig.3). The most affected zones are the Military Airport, the military barracks and roads and railways.
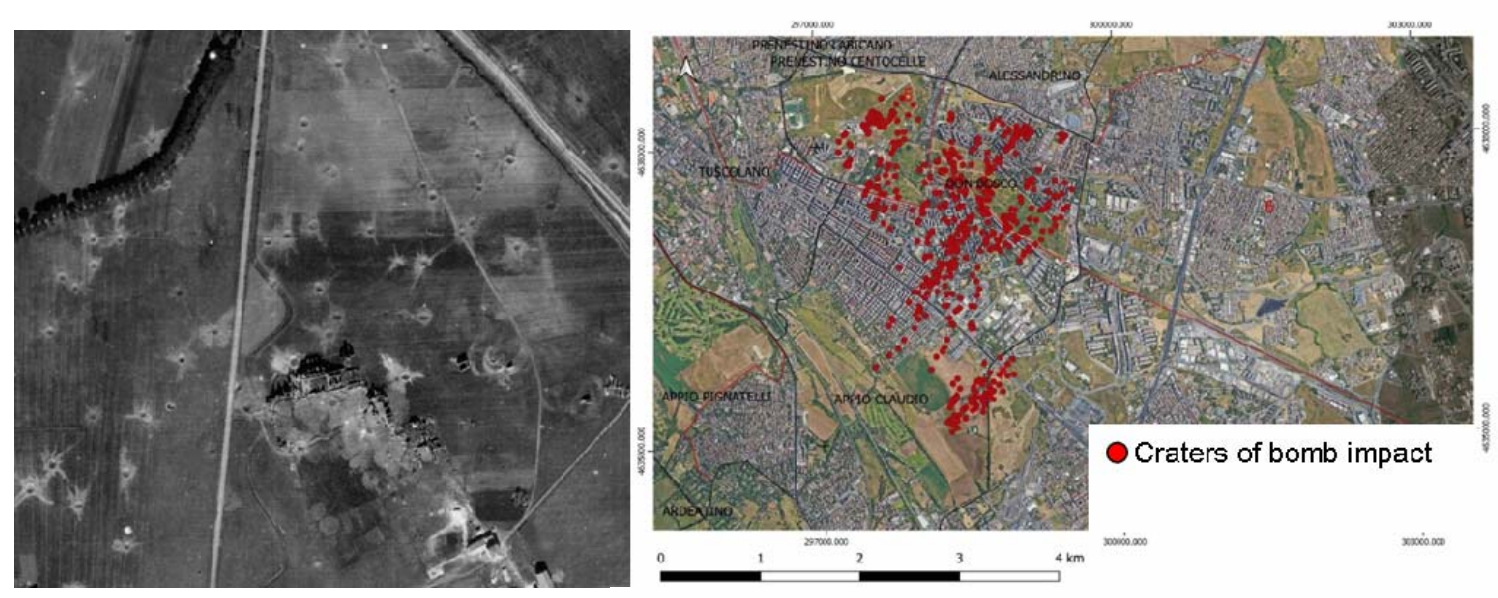

Fig.3: vectorization of bombing craters from RAF 1944photogram (orthorectified)in the area of Centocelle/Osteria del Curato 
With the historical DEMs (SARA 1927, RAF1944 and AM 1953), the underground quarry areas, the collapsed areas, the size and type of exploitation of the local tuff, the position of some of the entrances in the Borgata Gordiani / Centocelle and nearby Via Palmiro Togliatti (Colli Aniene) have been precisely identified. In the GIS environment and through the use of open-source software such as Cloud Compare and Gigamesh, it was possible to perform an evaluation of 2D and 3D features, which allowed the evaluation of the size, depth and relative age of the open-cast quarry structures (trenches, access ramps and terraces) and of the sinkholes developed for the collapse of underground environments (an example of the study of a collapsed quarry structure in the zone of Borgata Gordiani is reported in fig.4). Furthermore, the vectorization of these features allows obtaining cartographic layers that can be used in the subsequent phase of cross-matching of all the factors under study, aimed at evaluating the matching between the possible factors considered, which, in combination with environmental factors, may have favoured sinkholes events in subsequent periods.

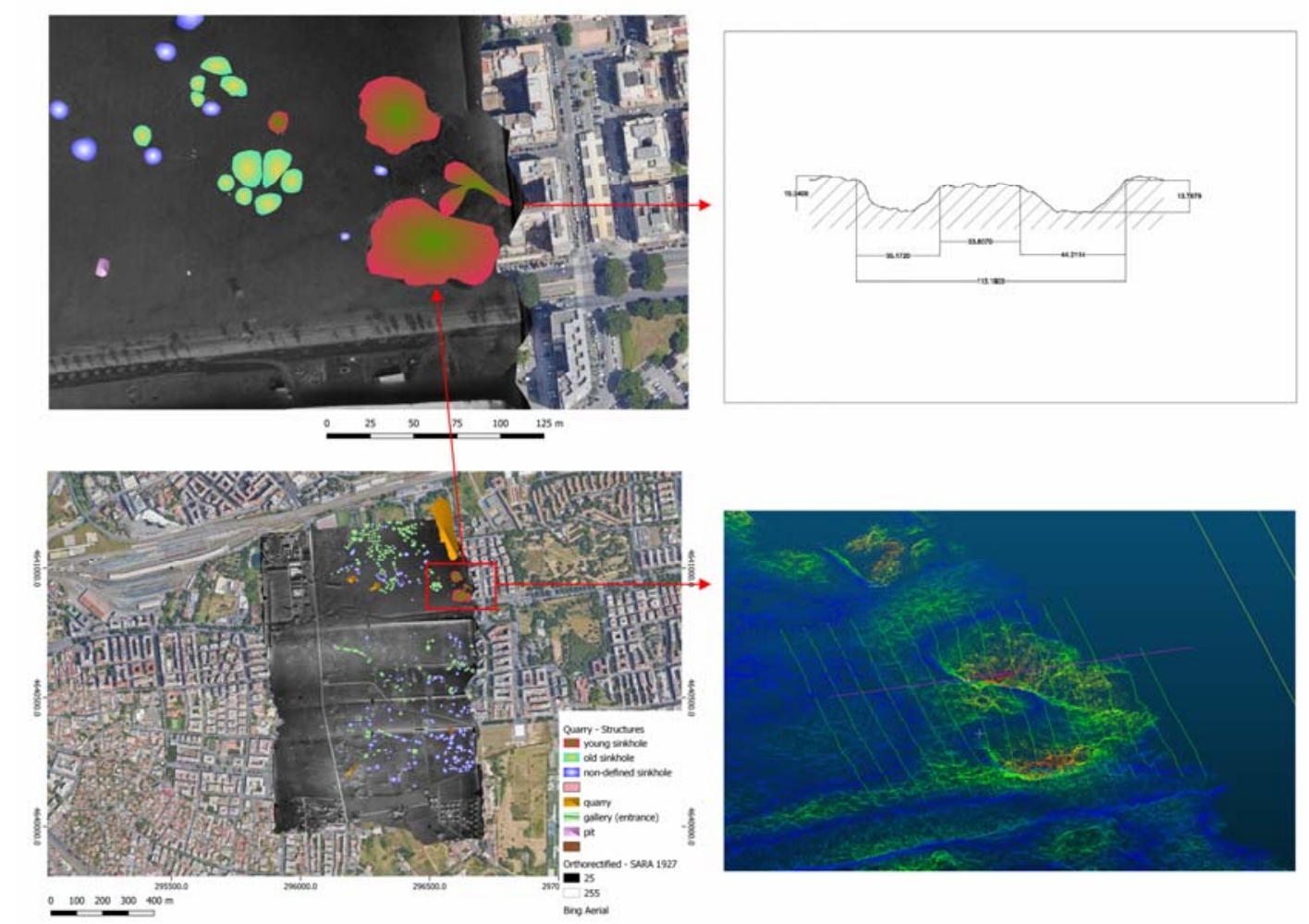

Fig.4: identification of the structures of quarry and sinkholes from historical photograms of SARA 1927 (orthorectified frames and 3D model)

\subsection{SAR time series interferometric analysis and cross-correlation with anthropogenic factors}

The two PS datasets, extracted from the SAR Cosmo-SkyMed Ascending and Descending time series, time of interest 2016-2021, and interpolated with the Musa tool (fig.5) were analyzed with the aim of identifying significant distributions of cumulative annual velocity values, in accordance with anthropogenic factors, if any. A statistical analysis of clusters and outliers on the distributions has been applied to visualize the presence of significant clusters to check if subsequent interpolations can correctly identify the same grouping of values extracted by this statistic tool. This analysis produces outputs in vector form that can be used to evaluate the position of the so-called hot and cold areas, whose CoType (classification of the type of clusters and outliers) value is expressed as LL (Low-Low) and HH (High-High). These are the real significant clusters, consisting of groups of coherent points of negative values surrounded by negative values (that can indicate a subsidence movement) and positive values surrounded by positive values (that can indicate an uplift). Low-Low and High-High PS clusters have been converted into polygon vectors, allowing to visualize the subsidence areas easily. The slight-uplift areas are of lesser importance for the intents of the work. Interpolation maps (fig.5) and clusters show are in good accord with the clusters distribution, allowing the identification of hot and cold areas with higher detail. The significant values from $-2.5 \mathrm{~mm}$ till 2.5 mm_yr velocities have been visualized with a customized symbology in a red-to-green chromatic scale (besides the interpolation maps for AOI2 and for the sub set of ColliAniene that has a wider range of values, in fig. 8 and fig.11). The second type of graduated chromatic scale, red-yellow, was allocated for the values from -2.5 to 0 , excluding the non-significant positive values, set as transparent. 

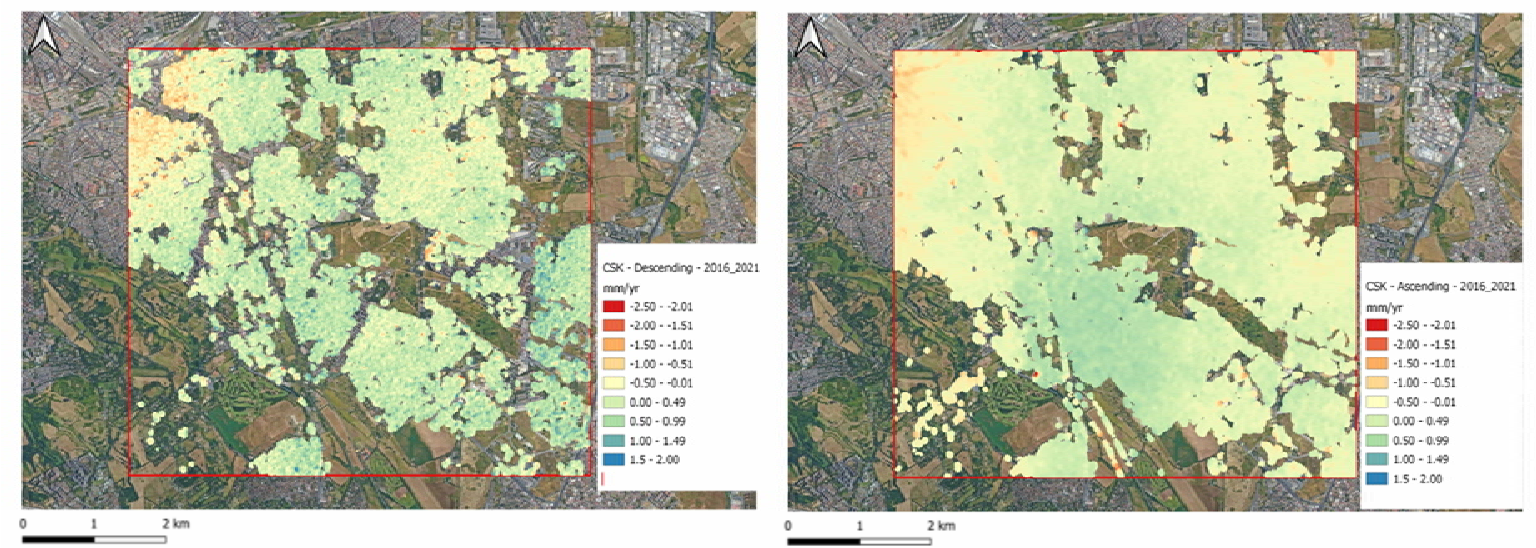

Fig.5: interpolations of PS datasets extracted with MUSA interpolation tool

The zonation of values was subsequently interpreted considering the factors taken into consideration: the bombing events, the presence of quarry structures and the identification of recent sinkhole events. Using these polygonized clusters with consistent negative values (Low-Low), a quick check of the incidence of recent sinkholes events, registered in vector format, in the aforementioned clusters (which therefore show possible slight subsidence) was carried out (fig.6), finding a percentage of $70 \%$ of the events in areas of Low-low clusters compared to the remaining $30 \%$ of the events in High-High clusters (areas that can be considered stable).
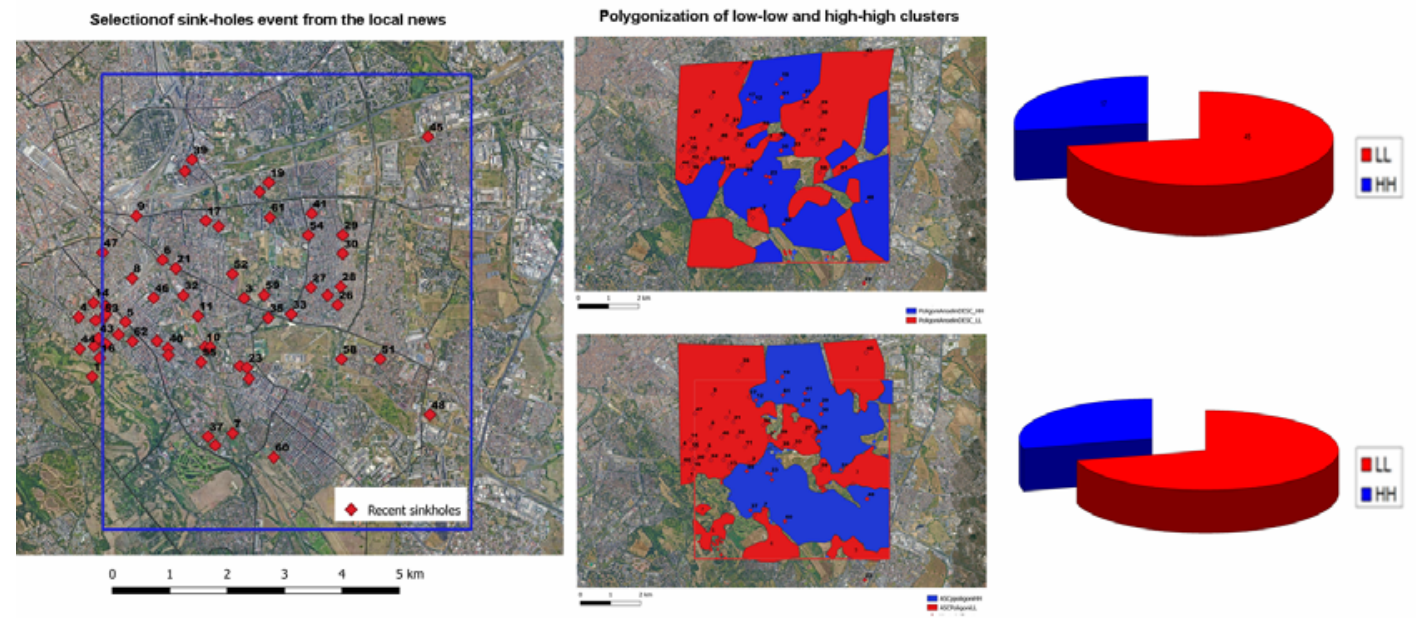

Fig.6: cross matching of sinkhole events in Rome (picture on the left) and the polygonized Clusters LL and HH and the relative incidence statistic, represented with the cake diagrams to the right.

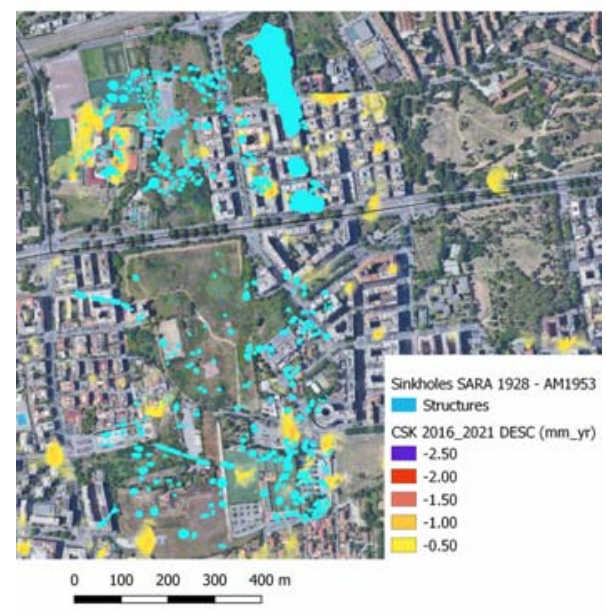

Fig.7: interpolated map of CSK (Descending, symbology in the legend) and the localization of quarry structures from SARA1928, detail on Borgata Gordiani. 
A preliminary agreement is also found in the areas where the quarry structures and sinkholes had been identified in the orthorectified frames (SARA 1928, RAF 1944, AM 1953). Interesting is the concomitance between the extension of the sinkholes in Borgata Gordiani (Fig.7) and in the Casilino district and the yellow-red spots in the interpolation maps in the same neighbourhood. The zone of Borgata Gordiani was also hit point of several bombing attacks, and it is also represented in the sinkhole vector layer by several events which took place in recent times showing, also in this case, a possible correlation with the informative layers

The same situation is also found with the raster relating to the descending dataset, shown in the Fig. 5. An area of interest is also that at the north of the intersection between Via Palmiro Togliatti and the A24 (Colli Aniene quarter, fig.8), in which a large quarry structure and some sinkholes can be identified in one historical photogram of AM1953. The same area is also identified by slightly negative values in the descending interpolation maps.
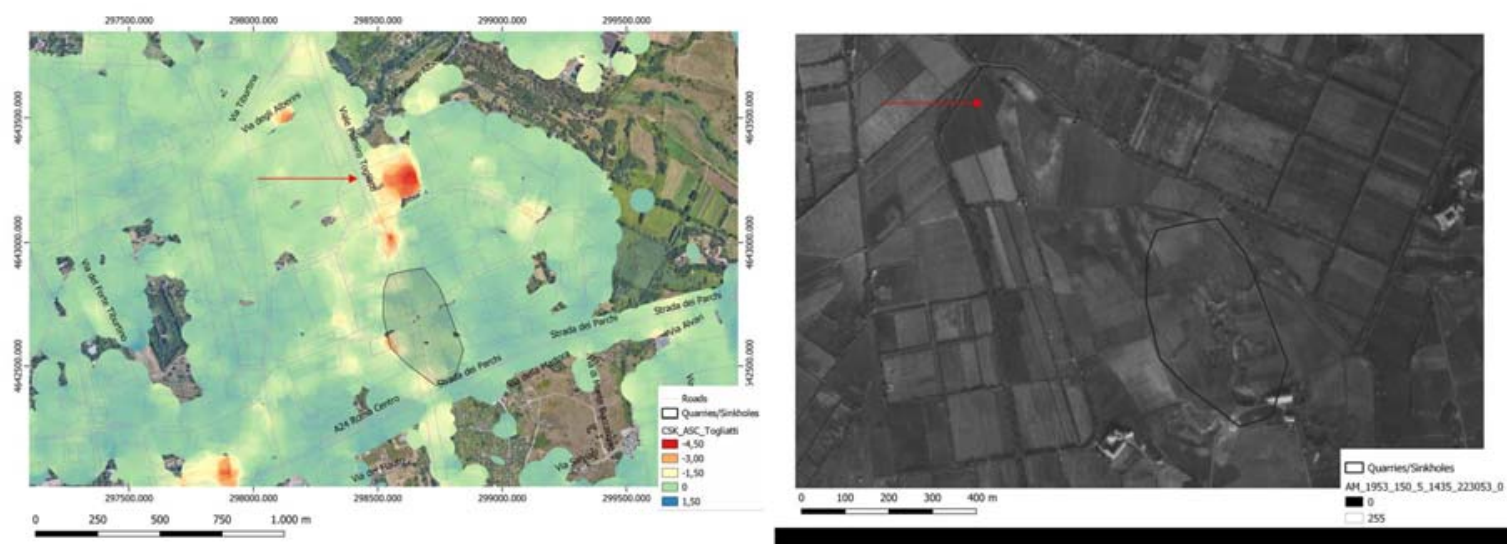

Fig.8: interpolated map of CSK (Ascending, symbology in the legend) and the localization of quarry structures from AM1953, detail on Colli Aniene (one well visible structure is delineated with a black polygon, while a possible second one is pointed with a red arrow).

Furthermore, in the districts with a higher frequency of bombing events (Tuscolano and Prenestino-Centocelle districts which have a frequency of 6 bombing events in a year, especially in strategic areas such as some connection roads such as Via del Mandrione and Casilina, stations and railway junctions, airports) a corresponding cold cluster is also highlighted in the interpolation maps (North-West quadrant), visible as an elongated yellow spots placed along the roads, allowing a preliminary hypothesis of a possible correlation (fig.9).
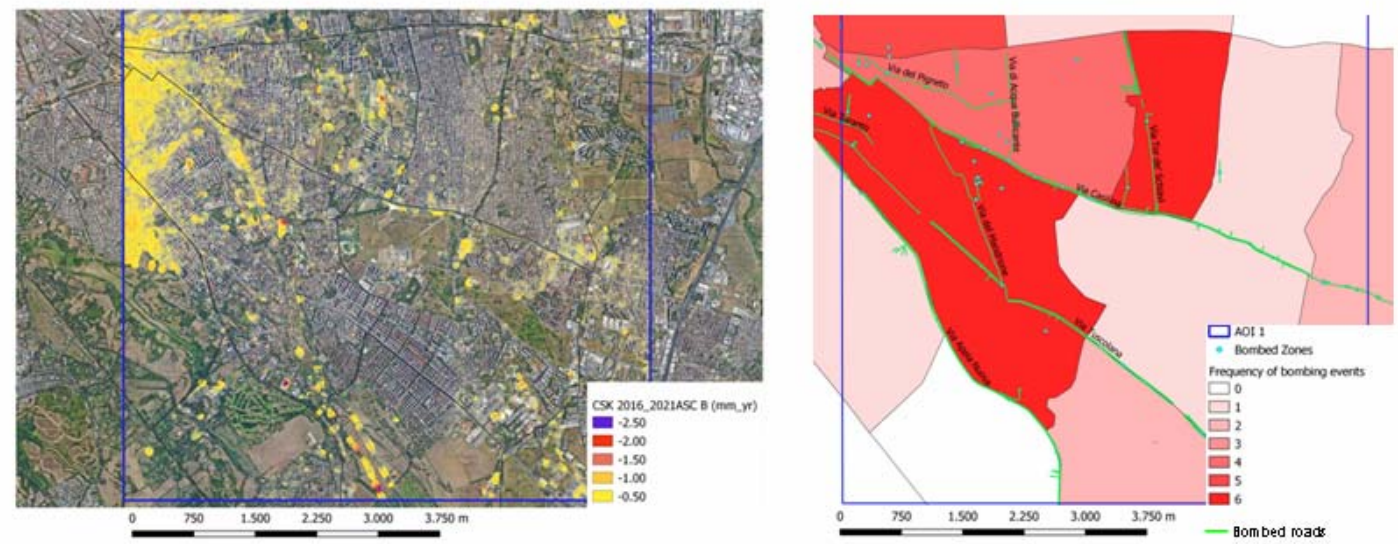

Fig.9: correlation between the interpolation map (Ascending, symbology in the legend) and bombing events -frequency values are shown in polygon form, white-to-red graduated symbology, the vectorization of roads in green lines, and the blue points additional areas that underwent air attacks

Furthermore, significant PSs have been chosen in the Low-Low clusters in areas affected by structural failure events for the detailed study of the time series (fig.10). The cases chosen are in the areas of Via del Mandrione (the road was often closed due to the presence of chasms caused by an advanced state of decay of the underground) and Tor de Schiavi (the park of Tor Fiscale is known for the presence of an extensive network of underground quarries and large sinkholes both in the park area and in some urban zones nearby). The time series extracted in vicinity of the 
places of sinkholes show a subsidence-like trend. However, a slightly noisy trend appears, affecting the time series, which is due mainly to residual temporal and geometrical decorrelation. The interpolation method, which filters noisy signals, facilitates the interpretation of the PS trend representing averaged results. In fact, the significant velocity (mm_yr) values are enhanced in the raster output, and the distributions are smoothed.

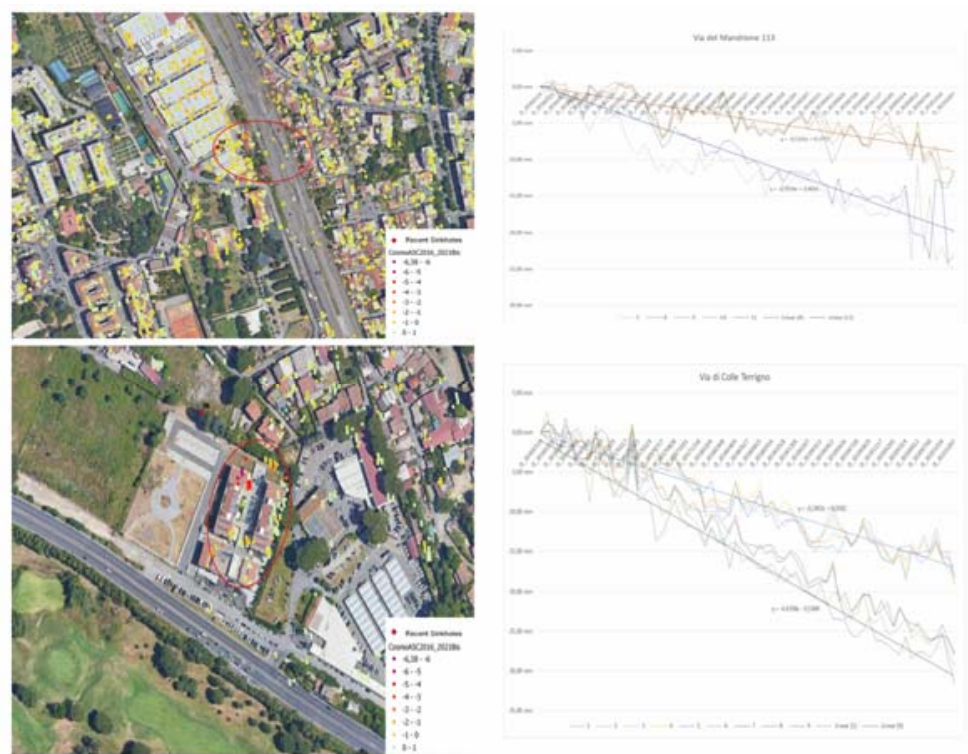

Fig.10: two examples of time series and the respective PS

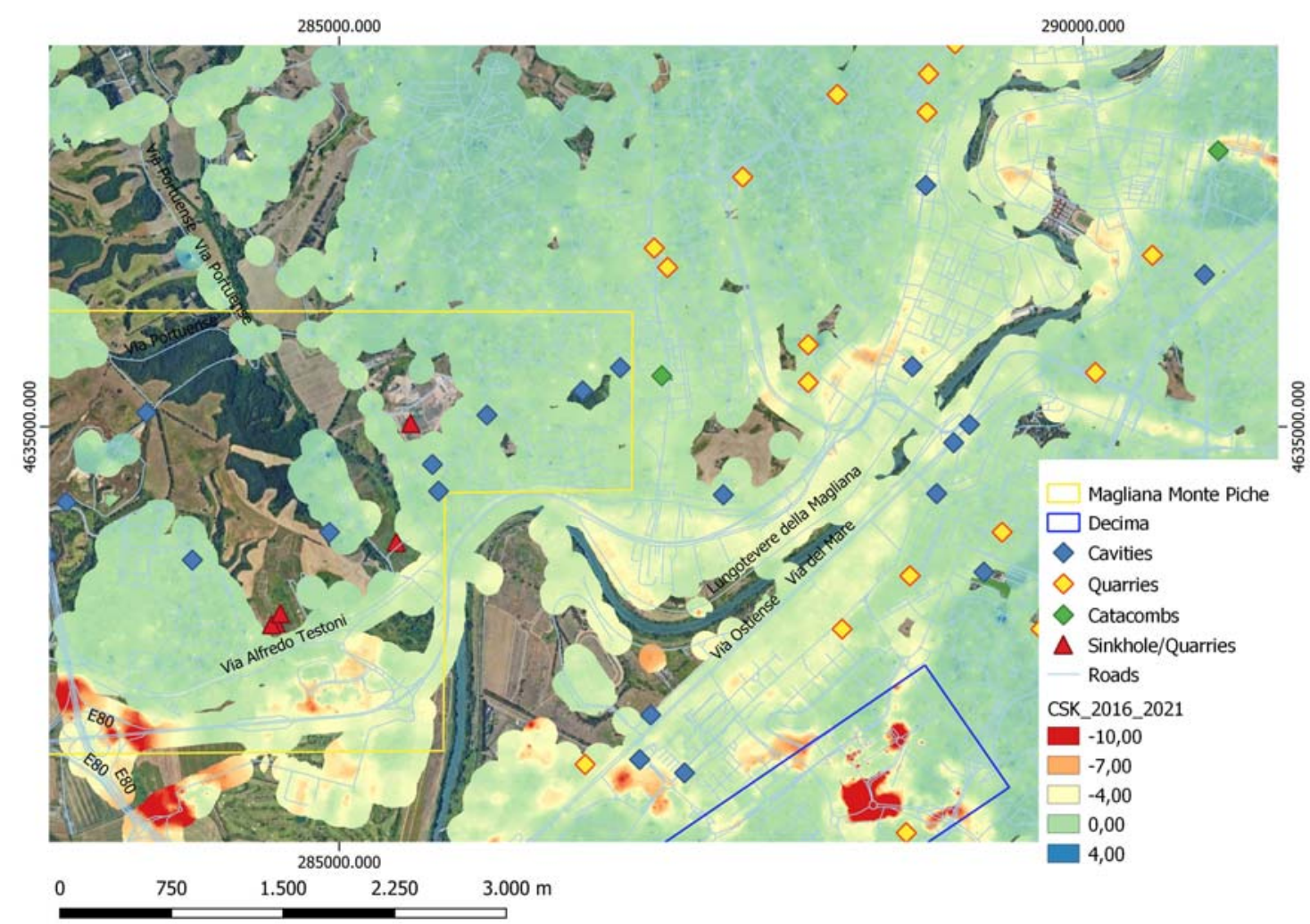

Fig.11: interpolated map of CSK (Ascending, symbology in the legend) and the localization of quarry structures (the vector layer Sinkholes/Quarries comes from a virtual survey of the basemap in Google Earth, while the other vector layers on Cavities, Quarries and Catacombs have been vectorized from Ciotoli et al. 2013, fig.1), detail on the Fosso della Magliana / Monte delle Piche zone and Decima neighbourhood.

The second area of interest, in the Magliana district (AOI2), was selected because of the incidence of sinkholes phenomena in road infrastructures (in Via Fosso della Magliana as an example) and the presence of ancient and 
modern quarry structures, for the exploitation of gravel, easily visible in its vegetated zones (for example in Monte delle Piche or near Corviale). However, the presence of these large green parks does not allow easy interpretation of the PS (interpolated map fig.11), so a different approach has been devised for this zone by processing SAR intensity time series.

Above all, this additional approach allowed understanding whether if quarries or sinkhole areas, characterized by vegetation cover with different soil moisture contents, are distinguishable using multitemporal approaches with SAR intensity data. For this aim, the Intensity Time Series stacking has been executed with the SARScape module (Envy), composed of several steps that allow pretreatment of the dataset, such as the Multilooking, Coregistration, De Grandi Multi-temporal Filtering, Geocoding and Radiometric Calibration. The final step is the extraction of Multi-Temporal "CovMinGrad" raster in RGB, shown in the picture (fig.11). The generation of terrain geocoded sigma nought data (the backscattering coefficient expressed per dimensional unit of ground area) allow the evaluation of reflection characteristics of the illuminated area. This value is a function of the intensity variation related to temporal changes in the local backscatter signals. The RGB image is composed of the three components, expressed in the three channels: Coefficient of Variation index (expresses the relative value of ratio STD/mean) in the red channel, that gives the idea of the relative width of dispersion of the values through time, the minimum index in the green channel and the maximum absolute variation in the time series, the gradient, in the blue channel. Therefore, it is expected that the red areas pixels express the presence of a relative deviation from the mediate value. The blue areas are those that have a maximum absolute value of variation between consequent dates. Green areas are instead those characterized by a low-variation intensity values, where also the contribution of red and blue channels are the lowest, letting the green the sole contributor to the RGB composite. In the purple areas, a combination of red and blue generally express wide variation of the backscatter signal. Concerning the output in fig.11, some of these red or purple features can lie on different types of mining structures such as that of pingen, sinkholes (in ancient mining zones) or compressed flat areas, not very vegetated (typically in modern quarries). The redder pixels are mainly found on modern quarry areas, where there is no vegetation and the ground is flat and compressed by the action of machines and therefore, where the water can stagnate at the surface right after rainfalls but it can also evaporate quickly, causing very variable water content condition in short times, that don't really affect the soil moisture. The bluish-purple areas correspond to vegetated sinkholes where the water stagnates in the soil for longer time, causing a higher absolute variation in the intensity of the backscattering signal that can also be affected by consequent changes in the vegetative state of the covering plants. Green areas correspond to built areas whose humidity is not particularly variable and the absence of vegetation does not cause significant fluctuations in the reflection of the radar signal. Therefore, in vegetated areas, where the PS evaluation method cannot be satisfactorily applied, it is possible to apply alternative approaches using intensity images and the evaluation of variation factors in change detection conditions, with the aim to identify structures connectable to ancient and recent quarries.
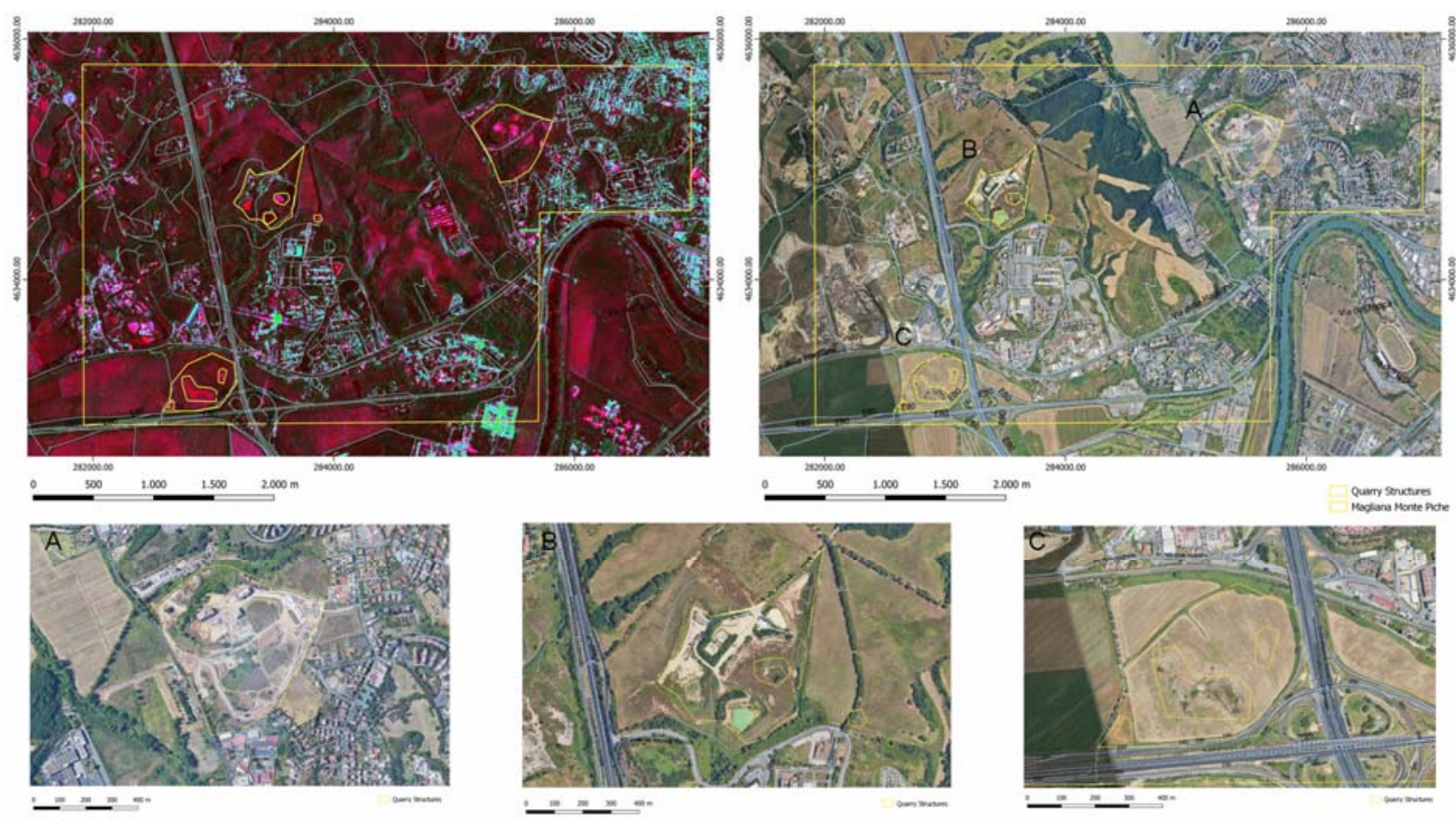

Fig.11: multitemporal intensity feature extraction from intensity dataset in the area of Magliana, subarea Fosso della Magliana. In the frames below (A, B, C) details of the quarry structures visible from virtual survey in Google Earth. 


\section{DISCUSSION}

The analytical procedure has been tested on these two case studies in the Rome area with the aim to identify its possibilities and issues in the study of structural vulnerability of roads, connected to anthropic factors. Each methodological step has been evaluated in the aftermath in its capacity to highlight the feature under examination. Concerning identifying the traces of quarries and sinkholes structures, the use of historical photograms to extract features from $2 \mathrm{D}$ and $3 \mathrm{D}$ products has proved very useful, allowing the examination of zones that are currently covered by dense urban textures. Additionally, the interferometric SAR proved to be suitable for recognizing the areas affected the most by the instability phenomenon. As a general observation, the interpolated products proved to be useful in the identification of statistically significant distributions of cumulated velocity values. Conversely, the sole examination of PSs time series trends, extracted from PS velocity values around isolated chasm events appears more challenging, as the plots are often affected by noise, and it is necessary to filter outliers and non-significant values. Generally, some problems can be defined regarding the use of the PS data (both interpolated or the point vector raw data) in the study of this phenomenon in urban areas: due to the radar shadow and the effects of double bounce, the narrow roads surrounded by high buildings are not always describable by PS, even considering both orbits and acquisition geometries. Furthermore, isolated and small events do not seem to affect the surrounding areas, as confirmed by the interpolate maps, which do not show a significant incipient subsidence trend to be used as a precursor indication. In the case of wide roads, especially when they have railroad tracks of materials with characteristics that favour a coherent backscattered signal (such as metals and concrete), it is possible to visualize significant PS distributions more clearly. The interpolation in these cases better allows the study of the interconnections between the aspects mentioned and the location of the chasms. Many large urban areas of Rome have good visibility in both datasets, especially with the ascending dataset, which has a higher point density. For some of the smaller areas, in some cases, It was found more favourable working with the descending dataset, which made it possible to effectively identify some slight subsidence movements, especially in the area of Borgata Gordiani, Centocelle, Colli Aniene and Tor Fiscale.

The results presented here are reported as application examples and the hypothesis are formulated on the available information. For a better definition of the problem, it is clear the need to carry out further investigations, also taking into account the geology, lithotypes and environmental conditions in the studied areas.

The use of feature extraction algorithms from intensity image datasets has allowed the identification of some traces in Magliana related to quarry structures such as humidity anomalies and vegetation zoning, allowing distinguishing dump heaps, trenches and sinkholes of different ages. In fact, on recent dump heaps, the vegetation is scarce and humidity can suddenly collect at the surface, after rainfalls, but because of the high compression of the soil, it doesn't affect soil moisture, remaining at the surface and evaporating fast. As a result, large puddles can be formed in such areas where the soil is remarkably compressed, creating an anomaly of intensity and loss of coherence, that is only temporary. This is valid also for recent quarry structures such as trenches and sinkholes, which are usually scarcely covered by vegetation. On old structures, the vegetation conditions can be variable, and the resulting pixel values depend mainly on the type of soil that usually forms in such depression zones and their capacity to drain or collect water and the vegetation condition.

\section{CONCLUSIONS}

The two case studies here presented and the simple analytical and study procedure applied allowed to evidence a possible correlation between anthropic factors that can lead to the development of chasms in the urban texture. In turn, the new insight has also produced new questions and the need for additional deepening of the research. For example, several cities in Italy between 1940 and 1945 underwent air bombing attacks, especially those with strategic functions, such as industrial and harbour areas [21]. The city of Naples, for example, has a comparable combination of factors to that of Rome because also there the pyroclastic materials from Campi Flegrei Volcanic district has been exploited for centuries, also leaving there a wide network of hypogea that could have been similarly affected by the bombing attacks of the II World War. Therefore, a necessary extension of this work is the validation of the method in other study areas to better understand the limits of the method and the possibility of extending the results to different scenarios.

The classical monitoring method with SAR interferometry was evaluated as a good expeditious approach, albeit with limitations relating to large urban green areas and zones affected by radar shadow. A further study aimed at the possible resolution of the vegetation cover issue can be identified by using alternative bands, such as L-band datasets for the extraction of PS, to be used to integrate the $\mathrm{C}$ and $\mathrm{X}$ band products. The relevance of the topic under discussion and its impact on safety in the urban areas and heritage preservation are currently fostering additional efforts to develop further and improve the analytical method and expand the study areas. 


\section{AKNOWLEDGMENTS}

This research here presented summarizes the results of a study conducted by the research group on the topic of ancient quarries in Rome. New results have been achieved, for some of the areas and topics here discussed, partially in the frame of the MOSCAS Project (Models and Tools for Characterization of Underground cavities), that we wish here to mention, funded by the Ministry of the Environment and Land and Sea Protection (now Ministry of Ecological Transition). The authors also would like to thank the Italian Body of Aerial Photogrammetric Surveys (EIRA) - ICCD for the distribution of the used photograms and ASI (Italian Space Agency) for the distribution of the SAR raw data for research purposes.

\section{REFERENCES}

[1] Berti G., Canuti P., \& Casagli N., "Criteri per la previsione e prevenzione del rischio connesso agli sprofondamenti catastrofici”, Le voragini catastrofiche, un nuovo problema per la Toscana. Att. Conv. 31 marzo 2000, GR. Regione Toscana, 8298 (2002).

[2] Intrieri E., Fontanelli K., Bardi F., Marini F., Carlà T., Pazzi V., Di Filippo M., Fanti R., "Definition of sinkhole triggers and susceptibility based on hydrogeomorphological analyses", Environmental earth sciences, 77 (1), 4 (2018).

[3] Sciotti M., "Engineering geological problems due to old underground quarries in the urban area of Rome (Italy)", Proceedings IV congressof the International Association of Engineering Geology, Vol I, 211-225(1982).

[4] Nisio S, Caramanna G, Ciotoli G Sinkholes hazard in Italy: first results on the inventory and analysis of some case studies. In: Parise \& Gunn (eds) Natural and Anthropogenic Hazards in Karst areas: Recognition, Analysis and Mitigation. Geo Soc Lond, Special Publications, 279, 23-45(2007).

[5] Ciotoli G., Corazza A., Finoia M.G., Nisio S., Serafini R., Succhiarelli C., "Sinkholes antropogenici nel territorio di Roma Capitale Anthropogenic sinkholes in the territory of Roma Capitale”, Mem. Descr. Carta Geol. d'It. XCIII, 143-182 (2013).

[6] Nisio S., "La carta delle cavità antropogeniche di Roma Capitale", Ordine degli Ingegneri della provincia di Roma, 2230 (2019).

[7] Fiore A., Lanzini M. "Problematiche di valutazione del rischio di crollo di cavità sotterranee", Geologia \& Territorio, 4 2006 / 1-2007, ,35-45 (2007).

[8] Ciotoli G., Nisio S. Serafini R, “Analisi della suscettibilità ai sinkholes antropogenici nel centro urbano di Roma,

XCIX”, Memorie Descrittive Carta Geologica d'Italia, 167 - 188 (2015).

[9] Intrieri E., Gigli G., Nocentini M., Lombardi L., Mugnai F., Fidolini F., Casagli N., "Sinkhole monitoring and early warning: An experimental and successful GB-InSAR application”, Geomorphology 241, 2015, 304-314 (2015).

[10] Jones C.E., Blom R.G., Bayou Corne, "Louisiana, sinkhole: Precursory deformation measured by radar interferometry", Geology 42 (2): 111-114 (2014).

[11] Ferretti, A., Marco, B., Fabrizio, N., Claudio, P., "Possible utilizzo di dati radar satellitari per individuazione e manotiraggio di fenomini di sinkholes". Nisio, S., Panetta, S., Vita, L. (Eds.), Proc. First Seminary on the State of the Art on Sinkhole Study and the Role of National and Local Administration on Land Management. APAT, Rome, Italy, 331-340 (2004).

[12] Tapete D., Morelli S., Fanti R., Casagli N., "Localising deformation along the elevation of linear structures: An experiment with space-borne InSAR and RTK GPS on the Roman Aqueducts in Rome, Italy", Applied Geography, 58, 65-83 "(2015).

[13] Jones C.E., "Capabilities, limitations and opportunities for studying sinkholes using synthetic aperture radar interferometry", 16th Sinkhole Conference, NCKI Symposium 8, 68-74 (2020).

[14] Scutti M., Scifoni S., Marsella M., Sonnessa A., Manunta M., "WHERE: World heritage monitoring by remote sensing,a pre-operational system to monitor UNESCO sites - A focus on the interferometry processing chain", The 33rd EARSeL Symposium 2013 3-6 June 2013 -Matera EARSeL,6-7 (2013).

[15] Marsella M., D'Aranno P.J.V., Scutti M., Scifoni S., Sonnessa A., Gonzales E.J.L., Bonano M., Manunta M., Pepe A. ; Ojha C. "Quantifying the effects of ground settlement on buildings by the exploitation of long term DINSAR time series: The case of Roma", 15th International Conference on Environment and Electrical Engineering, EEEIC 2015, Rome (Italy), 10-13 June 2015, EEEIC 2015 - Conference Proceedings, Article number 7165528, 2226-2230 (2015).

[16] D'Aranno P. J. V., Marsella M., Scifoni S., Scutti M, Bonano M., "Advanced DInSAR analysis for building damage assessment in large urban areas: an application to the city of Roma, Italy”, Proc. SPIE 9642, SAR Image Analysis, Modeling, and Techniques XV, 96420L (23 October 2015) (2015).

[17] D’Aranno P.J.V., Di Benedetto A., Fiani M., Marsella M., Moriero I., Palenzuela J.A., “An Application of Persistent Scatterer Interferometry (PSI) Technique for Infrastructure Monitoring”, Remote Sensing, 13(6), 1052 (2021).

[18] Celauro A, Marsella M. A., D’Aranno P. J. V., Maass A., Palenzuela Baena J. A., Guerrero Tello J. F., Moriero I., "Ancient Mining Landscapes and Habitative Sceneries in the Urban Area of Centocelle: Geomatic Applications for their Identification, Measurement, Documentation and Monitoring", The International Archives of the Photogrammetry, Remote Sensing and Spatial Information Sciences, Volume XLII-2/W11, 403-410 (2019).

[19] Gioacchini M. \& Massorbio G. "Bombardate l'Italia - Storia della Guerra di Distruzione Aerea 1940-1945”, Rizzoli

2007. 
[20] Naso G.L., "Memorie di Guerra - I bombardamenti del '43 a Porta Maggiore, Portonaccio e delle officine di Prenestina", ATAC, (2013).

[21] Baldoli C., "I bombardamenti sull'Italia nella Seconda Guerra Mondiale. Strategia anglo-americana e propaganda rivolta alla popolazione civile", Deportate, esuli, profughe - Rivista telematica di studi sulla memoria femminile, Dep n.13-14, 34-49 (2010). 